\title{
Consequences of Sharing Invisible Chronic Health Conditions at Work: Implications for Business Communication Education and Training
}

\section{Stephanie Kelly, Alfredo Romero}

\author{
North Carolina A\&T State University, Greensboro, NC, USA
}

Objectives: The present investigation sought to identify whether there was a need to add health diversity training into business communication curriculum and workplace trainings.

Methods: Individuals in the United States with chronic invisible illnesses, lifelong illnesses which are concealable, were surveyed to understand their experiences disclosing their health conditions at work. Qualtrics was used to obtain a random sample and distribute the online questionnaire. This method of solicitation resulted in 298 participants.

Results: Nearly half of the participants (48.99\%) reported negative experiences, ranging from social faux pas to bullying, after disclosing their health condition to a colleague. This paper provides a typology of eight negative experiences these individuals were subjected to after the disclosure of their health condition. Further, statistically significant patterns were identified that revealed that women and individuals with "other" invisible chronic illnesses were most likely to experience resentment from coworkers after their condition became known, individuals with musculoskeletal conditions were likely to experience an unwanted reduction of work, individuals in the medical field were more likely to experience bullying and social withdrawal by colleagues, and individuals in sales were more likely to have their abilities questioned.

Conclusions: The data suggests the need to add health diversity training into business communication courses and workplace training. In particular, it seems that there is a need to train individuals on the management of coworkers' health information and the treatment of individuals who have revealed an illness.

Key Words: Health, Diversity, Communication, Training, Business

\section{Introduction}

Most organizations require some form of diversity training that

Received: Aug 26, 2018 Revised: Sep 21, 2018 Accepted: Oct 2, 2018 Corresponding author: Stephanie Kelly

North Carolina A\&T State University, 1601 E. Market Street, Greensboro, NC 27411, USA

Tel: +1-336-285-4903, E-mail: sekelly@ncat.edu

This is an Open Access article distributed under the terms of the Creative Commons Attribution Non-Commercial License (http://creativecommons.org/licenses/ by-nc/4.0/) which permits unrestricted non-commercial use, distribution, and reproduction in any medium, provided the original work is properly cited.

Copyright $\odot 2019$ Korean Association for Business Communication. teaches employees how to talk about and approach diversity in culture, gender, and sex in the workplace (e.g., Bendick, Egan, \& Lofhjelm, 2001; Dipboye \& Colella, 2013; Kirby \& Harter, 2001; Mobley \& Payne, 1992; Sue 1991), with some recent attention to diversity training for spirituality in the workplace (Vogel, McMinn, Peterson, \& Gathercoal, 2013). Further, racial, generational, and gender diversity training has become increasingly more diffused throughout undergraduate curriculum in the last 10 years (Glenn, 2007; Heuman, 2018; Root, 2018). Yet, health diversity is not widely mentioned in the training or business education literature beyond sometimes noting the existence of 
non-discrimination policies and the treatment of persons with disabilities (Phillips, Deiches, Morrison, Chan, \& Bezyak, 2016).

Managing diversity is ultimately a business communication issue, where professionals must be trained in how to talk about and respond to diversity within the workplace. As Westerman, Miller, Reno, and Spates (2015) summarize, "Managing private health information in the workplace has become a salient communication issue for employees, supervisors, and organizations" (p. 378). Therefore, the purpose of this study is to address a hole in the literature: to identify whether there is a need to incorporate health diversity training in business communication curriculum and workplace training.

\section{Health Disclosure at Work}

"Managing private health information is a salient issue at work because telling coworkers about an illness can garner needed support but can also be stigmatizing, which is a particular concern of those with chronic illnesses" (Westerman et al., 2015, p. 380). While some medical conditions are apparent upon sight, others are invisible, meaning that they are only known to coworkers if the afflicted employee chooses to share them. For individuals who have an invisible chronic illness, the dilemma of choosing whether to disclose their condition at work can span across their lifetime as they weigh the benefits of potential support or accommodations against the potential risks of discrimination and social stigma. As such, the experiences of individuals with invisible chronic illnesses, those who could have hidden their illness indefinitely but chose to disclose, can offer unique insight into the reality of workplace health disclosures. Specifically, the present study sought to identify whether individuals with invisible chronic illnesses who have chosen to disclose their condition have had negative experiences with that disclosure and to examine those experiences.

Communication privacy management theory (CPM; Petronio, 2002) explains how people choose to disclose or conceal their personal information. Disclosure of private information is governed by privacy boundaries constructed by the information owner. These boundaries separate public from private content. Individuals who have an invisible chronic illness have the autonomy to decide whether their health information should be private or public information as others are not aware of an illness without the information owners' disclosure to at least one other individual. Like all information disclosers, the information owner expects that, if he or she shares personal information, the new information owner will follow the disclosure rules set for by the original owner (Petronio, 2002). (For example, if someone discloses their health condition to a coworker in confidence, they expect that coworker to keep their secret.) When these rules are not followed, however, the original information owner loses ownership of their personal information as it becomes public knowledge.

Individuals often hesitate to disclose their health information at work because they do not want to be discriminated against or judged (Vickers, 1997; Westerman et al., 2015). For example, Stewart et al. (2001) surveyed 378 breast cancer survivors about their workplace disclosure practices while they were undergoing cancer treatments. The authors found that $50 \%$ of participants disclosed at work to colleagues or their boss. Among these participants, $3 \%$ felt that they were unable to fulfill their job potential because they were discriminated against after their diagnosis. However, participants who disclosed their cancer diagnosis were overall more likely to continue working than those who did not. As such, choosing to disclose health information may provide the social support and/or understanding a person needs to be successful, but it also opens the door for judgment and discrimination.

Sometimes health information must be disclosed at work to explain coping or management techniques. Munir, Leka, and Griffiths (2005) found management of illness (for example, taking insulin injections at work) to be the greatest predictor of disclosing to coworkers. For individuals with short-term health conditions, the decision to disclose is temporal, but for individuals managing a condition across a lifetime, the decision to disclose is as chronic as their condition (Vickers, 1997).

The decision to disclose health information at work can be particularly difficult for individuals who have an invisible chronic illness. Vickers (1997) defines an invisible chronic illness as one that is "an ongoing condition; one which may be physical, emotional, judgmental, or cognitive; one that may not be curable... a condition that is not perceptible, not noticeable, not evident to others" (p. 241). Most research on health disclosure at work has focused on highly stigmatized health conditions. Infertility, IBS, mental health conditions, and HIV/ AIDS are the most widely recognized stigmatized health conditions, all of which are invisible and chronic (Cline \& McKenzie, 2000; Corrigan \& Watson, 2002; Greil, 1991; Munir et al., 2005). People with stigmatized health conditions do not disclose their conditions at work for fear of being discriminated against or socially isolated (Joachim \& Acorn, 2000; Vickers, 1997).

In 1997, Vickers called for increased research in the disclosure of chronic invisible illnesses at work when he noted that the presence of chronic invisible illness was on the rise in the United States. Based on the literature to date, Vickers (1997) was able to conclude that generally, chronically but undiscernibly ill individuals avoid disclosure to prevent being stigmatized or mistreated, but otherwise no further literature existed on the 
topic. Munir et al. answered Vickers' call for more research in 2005 and concluded more specifically that the motivations not to disclose included potential discrimination, decrease in social support, and firing. To date, no other studies have focused on this unique but prevalent population.

\section{Rationale}

Diversity training is a structured process that provides information for employees about how to react when they encounter diversity in the workplace (Dipboye \& Colella, 2013). Diversity training teaches respect for diversity and how to respond to diversity in such a way that it does not create discomfort for any parties. The current literature on workplace and classroom diversity training has a strong emphasis on providing cultural, sex, generation, and gender training (e.g., Bendick, et al., 2001; Crews, North, Thompson, \& 2001; Dipboye \& Colella, 2013; Glenn, 2000, 2007; Kirby \& Harter, 2001; Mobley \& Payne, 1992; Rucker, 2007; Sue 1991). However, no literature could be found that discusses the need to train business students or employees on how to respond when a coworker discloses their health information. Given the lack of literature, perhaps there is no need for diversity training regarding health disclosures. Perhaps the fear of stigma is no longer a concern for people with the option not to disclose, as Munir et al. found in 2005. If this is true, then individuals with invisible chronic health conditions may no longer need to be concerned with the risk of being stigmatized in light of disclosing their condition to coworkers. Therefore, the following research question (RQ) will be addressed:

RQ 1: How common is it for someone with an invisible chronic health condition to have a negative experience when a coworker learns of their condition?

If there is indeed a need for diversity training in health disclosures, meaning individuals are experiencing negative reactions to disclosing their invisible chronic condition, it would be useful for developing training to know what the range of the negative reactions have been. Therefore, the following research question will be addressed:

RQ 2: What negative experiences have individuals with invisible chronic health conditions had when a co-worker learned of their condition?

Finally, if indeed there is a need for diversity training regarding health disclosure, it would be useful to identify whether there are particular occupations with prevalent issues or particular types of health conditions that are prevalently stigmatized against. As such, the following research question will be addressed:

RQ 3: Are there any demographic patterns that predict how coworkers will negatively respond to learning of a participants' health condition?

\section{Methods}

\section{Procedure}

University IRB approval for the questionnaire was obtained before loading the questionnaire to Qualtrics, which was the direct participant contact. Qualtrics is a survey distribution company that charges researchers per completed questionnaire and offers a monetary incentive to participants, typically less than \$1 USD. From Qualtrics, participants received a link to an informed consent explaining the study as an attempt to understand how people communicate about their health at work. The consent form further explained that to be eligible to participate in this study, participants were required to be at least 18 years old, be currently employed, have "a non-visible or non-obvious disability, illness, impairment, or handicap," and have disclosed that condition to at least one coworker. Qualtrics randomly disseminated the questionnaire to their subject pool across the United States, soliciting an acknowledgement that participants were willing to participate and that they met the criteria. After acknowledging consent and affirming that eligibility requirements were met, participants were directed to the online questionnaire. On average, participants needed 5 minutes to complete the questionnaire.

\section{Participants}

All participants $(\mathrm{n}=298)$ self-reported to have a chronic, invisible health condition. Participants were asked at the beginning of the questionnaire, "Have you ever had a colleague respond negatively to learning your condition?" Because of the relevance of this item to the research questions, participant demographics are summarized in Table 1, broken down into groups who had and had not experienced a negative response from a colleague as a result of their invisible chronic illness being revealed. Participants were asked to identify their invisible chronic illness categorically by musculoskeletal, neurological, mental, or other. They were also asked to specify their condition. Examples of mental conditions included anxiety, dyslexia, and depression. Examples of musculoskeletal conditions include degenerative bone disorders, arthritis, and carpel tunnel syndrome. Examples of neurological conditions include neuropathy, Guillain Barre, and Renaud's. Examples of other conditions include hearing 
Table 1. Participant demographic information

\begin{tabular}{lll}
\hline Variable & \multicolumn{2}{c}{ Negative consequence } \\
& Yes ( $\mathbf{n = 1 4 6 )}$ & No ( $\mathbf{n = 1 5 2 )}$ \\
\hline Gender (\%) & 39.7 & 44.7 \\
Men & 60.3 & 55.3 \\
Women & $34.7(S D=9.63)$ & $36.4(S D=11.71)$ \\
Average age (yr) & & \\
Occupation (\%) & 2.1 & 2.6 \\
Agriculture & 11.6 & 8.6 \\
Education & 7.5 & 8.6 \\
Engineering & 9.6 & 11.2 \\
Medical & 1.4 & 0.7 \\
Military & 19.9 & 11.8 \\
Skilled labor & 21.9 & 17.8 \\
Sales & 26.0 & 38.8 \\
Other & & \\
Health condition & & \\
(\%, multi-select question) & & 27.0 \\
Musculoskeletal & 40.0 & 28.9 \\
Neurological & 41.1 & 58.6 \\
Mental & 69.2 & \\
Other & 34.7 & \\
Multiple & 60.3 & \\
\hline
\end{tabular}

disorders, vision disorders, and asthma.

\section{Instrumentation}

The questionnaire consisted of a combination of open-ended and closed-ended questions. Borrowing categories from the Invisible Disabilities Association (n.d.), participants were first asked whether mental, musculoskeletal, neurological, or other best described their condition and asked to specify the condition. They were then asked if they had ever experienced a negative reaction to disclosing their illness to a colleague and if so to describe the first incident in which a coworker negatively responded to their learning about their condition. Participants were asked to describe their first incident because while it was likely to be memorable, leaving the item open-ended to any incident was likely to garner responses specific to the worst incident. Therefore, asking about the first incident was more likely to result in data of a clear memory that represented a common negative response rather than an extreme incident. Finally, demographic information (i.e., sex, occupation, and age) was collected.

\section{Data Analysis}

Research question one was addressed through a simple percent- age. Research question two was addressed through thematic analysis (Miles \& Huberman, 1994) of the item, "Please describe the first time that a colleague reacted negatively to learning about your condition." Finally, to answer research question three, the themes generated from the thematic analysis were used as a coding scheme to complete a content analysis (Krippendorff, 1989). Researchers independently reviewed the data to identify whether identified themes were present within each response. Once both researchers independently coded the data, responses were compared. Next, eight logistic regressions were run (one per theme) to identify whether any of the themes were predicted by the collected demographic items. Results were computed as odd ratios for gender (men being the reference category), age, invisible chronic conditions (with none being the reference category), and the presence or absence of each occupation.

\section{Results}

Different analytical procedures were used to address each research question. The analyses and results are broken down in the following subsections.

\section{Research Question 1}

Research Question 1 asked which asked how common it is for someone with an invisible chronic health condition to have a negative experience when a coworker learns of their condition. Among the participants, 48.99\% ( $n=146)$ had experienced a colleague responding negatively upon learning about their health condition at their present job. Table 1, which provides a summary of participant demographics, displays the demographics of participants who had experienced a negative consequence from having their health condition revealed.

\section{Research Question 2}

Through the thematic analysis, researchers identified eight themes. Researchers first identified these themes through an independent review. Though their descriptors varied slightly during the independent review of the data, the researchers agreed upon eight themes and, ultimately, categorical names for those themes through a shared understanding. The themes are as follows.

\section{Reduction of Work}

Some participants described losing responsibilities at work as a result of their colleague learning about their condition, regardless of whether they were capable of handling their current workload. For some participants, this was a reduction of the 
number of tasks while for others it involved being stagnated in a position, unable to demonstrate that they had the skills to advance. The following quotes describe this theme:

- I was reprimanded for not being truthful about my disability and reassigned to another position after.

- They refused to promote me and found other reasons that were due to side effects of my disabilities.

- I was given less work because they thought I couldn't handle it mentally.

- Well they don't let me take on more work or responsibilities. Cannot advance at work no matter how many years I've been there.

\section{Resentment}

Some participants described feeling as though their coworkers perceived them to be a burden or resented accommodations they needed. Some responses described complaining about their work quality or perceived compensation directly to the participant, while others were made more publicly. The following quotes represent this theme:

- I needed my work area set up differently including things designed for left handers and a special mouse to help with carpal tunnel. I would get snide comments about why was I so special and if I can't do the job with [standard equipment].

- They bad-mouthed me and said I shouldn't be at my job.

- Turned me into my boss for "being outside of office to much" when I was dealing with side effects of my MSK privately away from clients.

- I had a colleague express their concern that I was impairing the success of the group because of my conditions.

\section{Dismissive}

A third theme was coworkers responding by dismissing the health condition as imaginary or non-intrusive. Participants who experienced this response described their coworkers brushing off the news of the participants' medical condition as though it could be ignored or willed away. The following quotes represent this theme:

- Because of my depression, they acted as if I was just faking it for attention or sympathy.

- I have been told many times that ADHD isn't real and that I just need to focus.

- I explained to a coworker why I could not make a grading deadline, and they accused me of being lazy and selfish. The standard "depression is all in your head, so snap out of it" reaction.

- She rudely and loudly made comments on how FM is not a disease. She inferred that it was, "Just to get pain meds or special attention."

\section{Disassociation}

Other coworkers were reported to withdraw from participants after learning about their medical condition. Participants described these coworkers as becoming aloof and uncomfortable after the medical disclosure. Quotes that represent this theme include:

- They distanced themselves.

- She seemed uncomfortable and seemed uninterested in me after that.

- They started treating me weird and wouldn't talk to me and weren't my friends anymore like I was stupid.

- I told the colleague how it works and they kinda fell off and really didn't want me to work there anymore.

\section{Social Faux Pas}

The fifth theme included a variety of social faux pas. These coworkers did not seem to respond in an intentionally negative way, but did respond in a way, that made the workplace more uncomfortable or difficult for participants. In short, the coworkers attempted to accommodate to the participants' unique condition, but actually made interactions worse with social blunders. Examples of quotes from this theme include:

- [They] began talking to me as though I were hard of hearing and had mental limitations.

- I [was] told to smile and be more sociable.

- They didn't think I could hear at all so they were writing everything down.

- They treated me like I was crippled.

\section{Bullying and Teasing}

Sixth, emerged the theme of bullying and teasing. These participants experienced more direct and aggressive responses from coworkers than those who fell into the resentment theme. Quotes that describe this theme are as follows:

- They spit on me and put dog poop in my food.

- The colleague would yell at me at busy times/force me to stay at the counter so I had to help customers and couldn't get away.

- They learned about my colostomy and started making fun of me. I quit.

- Said that I was mental.

\section{Slander and Gossip}

The seventh theme was experienced by individuals whose health information was shared by coworkers without participants' permission. By doing this, participants' health conditions 
became a topic of workplace discussion and sometimes ridicule. The following quotes represent this theme:

- They announced [my condition] loudly.

- They told everyone else about it and it became gossip.

- She was telling people at my job I was faking being sick.

- Walking past a communal room and heard her discussing my nervousness to others.

\section{Questioned Ability}

The final theme was experienced by participants whose coworkers immediately responded by asking them if they could perform the job they were already performing. Participants who fell into this theme had their capabilities doubted. Quotes that represent this theme include:

- They questioned my ability to perform the tasks I was given.

- I was trying to give him a description of a technical problem at work and could not get out a certain word. My coworker told me he did not understand how I could ever get my job completely done if I stutter so badly.

- Didn't think I was mentally capable of the job.

- They found out about it and then said I could not deal with certain customers.

\section{Research Question 3}

Research question three asked whether any demographic items (i.e., participants' sex, age, occupation, and category of invisible chronic illness) could predict how coworkers would respond negatively to participants. Inter-coder reliability for the content analysis was calculated using Cohen's kappa $(k=.95)$. Table 2 shows the percentage of respondents who identified with each theme. Notably, some responses represented more than one theme.

Results of logistic regressions predicting themes through

Table 2. Content analysis results for responses to, "Please describe the first time a colleague reacted negatively to learning how your condition inconvenienced you at work."

\begin{tabular}{lc}
\hline Theme & $\begin{array}{c}\text { Percentage of responses } \\
\text { represented (\%) }\end{array}$ \\
\hline Reduction of work & 11 \\
Resentment & 17 \\
Dismissive & 18 \\
Disassociation & 10 \\
Social faux pas & 12 \\
Bullying \& teasing & 39 \\
Slander \& gossip & 11 \\
Questioned ability & 19 \\
\hline
\end{tabular}

demographic variables are displayed in Table 3. In four out of the eight themes, being a woman increased the probability that a coworker would react negatively to disclosure, although the only statistically significant result found was with the reaction of resentment. In this instance, being a woman made it 315\% more likely that a coworker would respond negatively to disclosure. In all but one theme, getting older also increased the probability of coworkers responding negatively, although none of the results are statistically significant. Having a musculoskeletal condition increased the chances of negative responses for dismissive, faux pas, slander, resentment, and reduction of work, but the latter was the only statistically significant effect. Having a neurological condition increased the chances of negative reactions for disassociation, faux pas, bullying, and reduced work with no statistically significant predictors. With respect to mental conditions, dismissive, faux pas, bullying, and slander seem to increase the chances of negative reactions, although none of them are statistically significant. Having another condition also resulted in a statistically significant increase of resentment reactions.

Lastly, with respect to the occupations, working in the medical field dramatically increased the odds of experiencing disassociation and slightly increased the odds of experiencing bullying with a statistically significant probability, while being a sales professional statistically significantly predicted questioned ability. All in all, as an exploratory analysis, the results hint to the existence of systematic behaviors from coworkers when invisible chronic conditions are revealed that manifest differently through gender, age, and occupation. This is noteworthy considering the sample size and the fact that not all themes nor all conditions contained all occupations.

\section{Discussion}

The results of this study indicated that nearly half of the sample (48.99\%) had experienced negative consequences of disclosing their health condition at work. These individuals were spread across age groups, occupational types, and health conditions. As such, these negative issues appear to be well saturated throughout the workforce, implying that diversity training education does need to be expanded to include health conditions.

The eight themes that emerged from the data were a surprising result. Previous literature had only identified discrimination/stigmatization (similar to Questioned Ability), decreased social support (similar to Disassociation), and firing (similar to Reduction of Work) as potential consequences of disclosing chronic health conditions (Munir et al., 2005). Also expected in the data set was the theme of Slander and Gossip. CMP theory 
Table 3. Logistic regression results: Demographics as predictors of consequences (Odds Ratio (Standard Error))

\begin{tabular}{|c|c|c|c|c|c|c|c|c|}
\hline Parameter & Dismissive & $\begin{array}{l}\text { Disassocia- } \\
\text { tion }\end{array}$ & Faux pas & Bullying & Slander & $\begin{array}{l}\text { Questioned } \\
\text { ability }\end{array}$ & $\begin{array}{l}\text { Reduction of } \\
\text { work }\end{array}$ & Resentment \\
\hline \multirow[t]{2}{*}{ Women } & 1.10 & 0.70 & 0.87 & 0.78 & 3.18 & 2.09 & 0.64 & $4.15^{*}$ \\
\hline & $(1.67)$ & $(1.92)$ & $(1.81)$ & (1.49) & $(2.03)$ & (1.68) & $(1.81)$ & $(1.86)$ \\
\hline \multirow[t]{2}{*}{ Age } & 0.99 & 1.03 & 1.01 & 1.00 & 1.02 & 1.00 & 1.03 & 1.03 \\
\hline & $(1.03)$ & $(1.03)$ & $(1.03)$ & $(1.02)$ & $(1.03)$ & $(1.02)$ & $(1.03)$ & $(1.02)$ \\
\hline \multicolumn{9}{|l|}{ Occupation } \\
\hline \multirow[t]{2}{*}{ Education } & 0.73 & 7.20 & ND & 0.27 & ND & 2.52 & 2.92 & 0.54 \\
\hline & $(4.11)$ & $(3.45)$ & (ND) & $(3.91)$ & (ND) & $(2.26)$ & $(2.68)$ & $(2.49)$ \\
\hline \multirow[t]{2}{*}{ Engineering } & ND & 6.49 & 0.82 & 0.22 & 2.32 & 4.12 & 3.62 & 0.99 \\
\hline & (ND) & (3.75) & (3.36) & $(4.21)$ & $(2.65)$ & $(2.45)$ & $(2.72)$ & $(2.57)$ \\
\hline \multirow[t]{2}{*}{ Medical } & 0.32 & $14.88^{*}$ & 2.60 & $0.01^{*}$ & 1.22 & 2.05 & 0.79 & 0.71 \\
\hline & $(4.50)$ & $(3.35)$ & $(2.38)$ & $(4.40)$ & $(2.56)$ & $(2.37)$ & $(3.67)$ & $(2.32)$ \\
\hline \multirow[t]{2}{*}{ Military } & ND & ND & 6.79 & 0.46 & ND & 10.73 & ND & ND \\
\hline & (ND) & (ND) & $(5.13)$ & (7.11) & (ND) & $(5.04)$ & (ND) & (ND) \\
\hline \multirow[t]{2}{*}{ Skilled labor } & 0.25 & 1.95 & 1.01 & 0.12 & 1.93 & 1.12 & 1.22 & 0.39 \\
\hline & $(4.30)$ & (3.69) & $(2.32)$ & $(3.92)$ & $(2.05)$ & $(2.29)$ & $(2.55)$ & $(2.24)$ \\
\hline \multirow[t]{2}{*}{ Sales } & 0.43 & 2.15 & 1.67 & 0.25 & 0.25 & $5.66^{*}$ & 0.93 & 0.87 \\
\hline & (3.99) & (3.64) & $(2.15)$ & $(3.81)$ & (3.15) & $(2.01)$ & $(2.49)$ & $(1.96)$ \\
\hline \multirow[t]{2}{*}{ Other } & 0.69 & ND & ND & 0.23 & ND & ND & ND & ND \\
\hline & $(3.85)$ & (ND) & (ND) & $(3.74)$ & (ND) & (ND) & (ND) & (ND) \\
\hline \multicolumn{9}{|l|}{ Health condition } \\
\hline \multirow[t]{2}{*}{ Musculoskeletal } & 1.11 & 0.43 & 1.21 & 0.79 & 1.72 & 0.80 & $2.94^{*}$ & 1.40 \\
\hline & $(1.64)$ & $(2.13)$ & $(1.79)$ & $(1.48)$ & $(1.89)$ & $(1.66)$ & $(1.87)$ & $(1.72)$ \\
\hline \multirow[t]{2}{*}{ Neurological } & 0.63 & 1.70 & 1.25 & 1.51 & 0.96 & 0.64 & 1.33 & 0.70 \\
\hline & $(1.65)$ & $(2.07)$ & $(1.77)$ & $(1.48)$ & $(1.87)$ & $(1.64)$ & $(1.88)$ & $(1.72)$ \\
\hline \multirow[t]{2}{*}{ Mental } & 1.25 & 0.81 & 1.28 & 1.01 & 4.24 & 0.81 & 0.96 & 0.55 \\
\hline & $(1.73)$ & $(2.03)$ & $(1.91)$ & $(1.53)$ & $(2.46)$ & $(1.70)$ & $(1.89)$ & $(1.74)$ \\
\hline \multirow[t]{2}{*}{ Other } & 1.75 & 1.59 & 0.67 & 0.82 & 0.85 & 0.42 & 2.43 & $2.40^{*}$ \\
\hline & (1.64) & (1.98) & $(1.90)$ & (1.53) & $(2.00)$ & $(1.75)$ & $(1.84)$ & $(1.67)$ \\
\hline \multirow[t]{2}{*}{ Constant } & 0.55 & $0.01^{*}$ & $0.06^{*}$ & 2.43 & $0.01^{*}$ & $0.10^{*}$ & $0.02^{*}$ & $0.03^{*}$ \\
\hline & $(4.70)$ & $(6.30)$ & $(4.01)$ & $(4.21)$ & $(6.17)$ & $(3.36)$ & $(4.89)$ & $(3.37)$ \\
\hline Observations & 133 & 141 & 126 & 146 & 124 & 143 & 141 & 141 \\
\hline
\end{tabular}

Note. ND = not determined.

${ }^{*} p<0.05$.

warns that once information is disclosed, the information owner no longer has control over where the information travels. As such, unapproved sharing is the theory's primary warning for health information owners who consider disclosing. However, four of the themes that emerged from the data were not identified in the previous literature:

- Resentment

- Dismissive

- Social Faux Pas

- Bullying and Teasing
Not only was the presence of these new themes unpredicted by the literature, but they were also more common in this sample than three of the four themes the literature had previously recognized (see Table 2). As such, these results indicate that there are more common risks realized by individuals who choose to disclose their invisible chronic health condition than are currently recognized by the literature. As such, further investigation is needed to identify the classroom interventions needed to prevent our students from engaging in these discriminatory behaviors once they enter the workplace.

Also unique to this dataset were the statistically significant 
patterns of women and individuals with other conditions being more likely to receive the response of resentment, of individuals with muscular skeletal conditions being more likely to have their job responsibilities taken away, of salespersons being more likely to have their abilities questioned, and of medical professionals being more likely to experience disassociation or be bullied. That this is experienced in the medical field, where colleagues are more likely to already be knowledgeable about their illnesses, is especially concerning. This indicates that education about the illness is not likely the proper approach for training, but rather that training on empathy and social awareness is needed. In short, the training needs to focus on communication.

\section{Implications for Business Communication Education}

Most communication training happens within the college classroom, so it falls upon business communication educators to discuss diversity within the classroom. The results of this study indicate that there is a need for diversity training regarding the disclosure of health information. The data indicate that the training needs to be robust, covering topics from inappropriate accommodations (social faux pas) to anti-bullying. As such, data indicate that at a minimum, the following topics should be included in health diversity training for business communication students and on the job for employees:

- Do not share another employee's health information except in extraordinary, high risk situations.

- Do not treat another employee differently if you learn that they have a health condition unless they request it.

- Do not assume that a health condition affects someone's work quality.

- Do not dismiss a health condition as imaginary.

- The data also indicate that health diversity training may be a good time to remind students and employees of anti-bullying policies.

\section{Conclusion}

This study provides direction for future research in business communication curriculum and workplace training regarding diversity and the unique situation of workers with invisible chronic illnesses. Though this sample focused on this particular population due to their unique ability to hide their condition across a lifetime, the study may have limited the types of health discrimination that take place in the workplace because of this sample bias. The use of Qualtrics limited potential participants to individuals who are comfortable using a computer. Additionally, Qualtrics does not provide a response rate. Further, organi- zational tenure, income, and education level were not collected, which could have been informative variables. This sample was also limited to the United States. Thus, future research could benefit from a more robust sample with a more robust collection of demographic variables. As such, this study serves as a stepping stone for the literature but should not be considered to have provided a complete typology of reactions to health disclosures at work.

\section{References}

Bendick, M., Jr., Egan, M. L., \& Lofhjelm, S. M. (2001). Workforce diversity training: From anti-discrimination compliance to organizational development. Human Resource Planning, 24(2), 10-25.

Cline, R. J. W., \& McKenzie, N. J. (2000). Dilemmas of disclosure in an age of HIV/AIDS: Balancing privacy and protection in the healthcare context. In S. Petrino (Ed.), Balancing the secrets of private disclosures (pp. 71-82). Hillsdale, NJ: Lawrence Erlbaum Associates.

Corrigan, P. W., \& Watson, A. C. (2002). The paradox of self-stigma and mental illness. Clinical Psychology-Science \& Practice, 9(1), 35-53.

Crews , T. B., North, A. B., \& Thompson, S. L. (2001). Diversity today: Challenges and strategies. National Business Education Association Yearbook 2001 (pp. 95-111). Reston, VA: National Business Education Association.

Dipboye, R. L., \& Colella, A. (Eds.). (2013). Discrimination at work: The psychological and organizational bases. Nawah, NJ: Psychology Press.

Glenn, J. M. (2000). Managing cross-generational diversity. Business Education Forum, 54(3), 16-19.

Glenn, J. M. L. (2007) Generations at work: The new "diversity". Business Education Forum, 62(1), 6-12.

Greil, A. L. (1991). A secret stigma: The analogy between infertility grand chronic illness and disability. Advances in Medical Sociology, 2(1), 17-38.

Heuman, A. N. (2018). Illuminating everyday performances of privilege and oppression. Communication Teacher, 32(1), 30-35.

Invisible Disabilities Association. (2018). How do you define invisible disability? Retrieved from https://invisibledisabilities.org/ what-is-an-invisible-disability

Joachim, G., \& Acorn, S. (2000). Stigma of visible and invisible chronic conditions. Journal of Advanced Nursing, 32(1), 243-248.

Kirby, E. L., \& Harter, L. M. (2001). Discourses of diversity and the quality of work life: The character and costs of the managerial metaphore. Management Communication Quarterly, 15(1), 121-127.

Krippendorff, K. (1989). Content analysis. In E. Barnouw, R. Bradley, S. MacDonald, \& P. R. Zimmerman, P.R. (Eds.), International 
encyclopedia of communications (Vol. 1, pp. 403-407). New York, NY: Oxford University Press.

Miles, M. B., \& Huberman, A. M. (1994). An expanded sourcebook: Qualitative data analysis (2nd ed.). Thousand Oaks, CA: Sage.

Mobley, M., \& Payne, T. (1992). Backlash! The challenge to diversity training. Training \& Development, 46(12), 45-52.

Munir, F., Leka, S., \& Griffiths, A. (2005). Dealing with self-management of chronic illness at work: Predictors for self-disclosure. Social Science and Medicine, 60(6), 1397-1407.

Petronio, S. (2002). Boundaries of privacy: Dialectics of disclosure. Albany, NC: State University of New York Press.

Phillips, B. N., Deiches, J., Morrison, B., Chan, F., \& Bezyak, J. L. (2015). Disability diversity training in the workplace: Systematic review and future directions. Journal of Occupational Rehabilitation, 26(3), 264-275.

Root, E. (2018). Staging scenes of co-cultural communication: Acting out aspects of marginalized and dominant identities. Communication Teacher, 32(1), 13-18.

Rucker, J. (2007). Generational diversity in the workplace: Business educators can help students prepare. Business Education Forum,
62(1), 4-12.

Stewart, D. E., Cheung, A. M., Duff, S., Wong, F., McQuestion, M., Cheng, T., ... Bunston, T. (2001). Long-term breast cancer survivors: Confidentiality, disclosure, effects on work and insurance. Psycho-Oncology, 10(3), 259-263.

Sue, D. W. (1991). A model for cultural diversity training. Journal of Counseling and Development, 70(1), 99-105.

Vickers, M. H. (1997). Life at work with 'invisible' chronic illness (ICI): The 'unseen', unspoken, unrecognised dilemma of disclosure. Journal of Workplace Learning, 9(7), 240-252.

Vogel, M. J., McMinn, M. R., Peterson, M. A., \& Gathercoal, K. A. (2013). Examining religion and spirituality as diversity training: A multidimensional look at training in the American Psychological Association. Professional Psychology: Research and Practice, 44(3), 158-167.

Westerman, C. Y. K., Miller, L. E., Reno, K. M., \& Spates, S. A. (2015). Sharing personal health information at work: What is appropriate and expected in organizations? Communication Studies, 66(3), 378-397. 